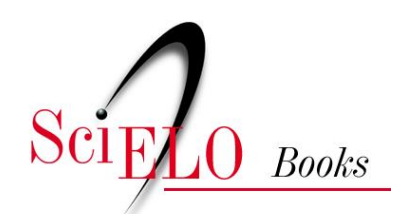

\title{
Experiencias de buenas prácticas \\ 5. ¿Estudiantes aburridos o propuesta pedagógica poco motivadora? - Experiencia de inclusión significativa de las TIC en los procesos de enseñanza y aprendizaje
}

\author{
Evelina Mariel Lamberti
}

\section{SciELO Books / SciELO Livros / SciELO Libros}

MARIEL LAMBERTI, E. ¿Estudiantes aburridos o propuesta pedagógica poco motivadora? Experiencia de inclusión significativa de las TIC en los procesos de enseñanza y aprendizaje. In: GALLEGOS NAVAS, M., ed. La inclusión de las TIC en la educación de personas con discapacidad: relatos de experiencias [online]. Quito: Editorial Abya-Yala, 2019, pp. 85-102. ISBN: 978-9978-10-495-8. https://doi.org/10.7476/9789978104958.0008.

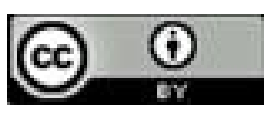

All the contents of this work, except where otherwise noted, is licensed under a Creative Commons Attribution 4.0 $\underline{\text { International license. }}$

Todo o conteúdo deste trabalho, exceto quando houver ressalva, é publicado sob a licença Creative Commons Atribição 4.0.

Todo el contenido de esta obra, excepto donde se indique lo contrario, está bajo licencia de la licencia $\underline{\text { Creative }}$ Commons Reconocimento 4.0. 
En la figura anterior se observa hay un incremento en el sentimiento de agrado por las materias que anteriormente eran rechazadas por los estudiantes.

\section{5. ¿Estudiantes aburridos o propuesta pedagógica poco motivadora? - Experiencia de inclusión significativa de las TIC en los procesos de enseñanza y aprendizaje}

"La verdadera educación consiste en obtener lo mejor de uno mismo. ¿Qué otro libro se puede estudiar mejor que el de la Humanidad?"

(P. Freire)

Escuela Normal Víctor Mercante-Nivel Superior

Argentina

Córdoba

Responsable: Lamberti Evelina Mariel

Gestores de la práctica: equipo directivo de la institución educativa, compuesto por: Prof. Petrucci Marcela - Directora y Lic. Tesan Luciana - Vicedirectora

Para enfrentar las necesidades de aprendizaje de un grupo de estudiantes ( 4 estudiantes con discapacidad intelectual 1 estudiante con Síndrome de West) esta práctica resalta dos aspectos de la dinámica pedagógica. En ese sentido, la práctica docente buscó promover y estimular en los estudiantes la resolución de problemas en el contexto real, así como, mejorar su capacidad de expresión oral, y la comprensión lectora a través del uso de varios dispositivos tecnológicos que se constituyeron en apoyos efectivos en el logro de los objetivos propuestos.

\section{Motivación}

De acuerdo a lo que establece la Ley de Educación Nacional, en el art 41: La Educación Especial es la modalidad del Sistema Educativo destinada a asegurar el derecho a la educación de las personas con discapacidades, temporales o permanentes, en todos los niveles y modalidades del Sistema. Se rige por el principio de inclusión y brinda atención educativa a todas aquellas problemáticas específicas que no puedan ser abordadas por la educación común (Congreso de la Nación Argentina, 2006, p. 9). 


\section{6}

En este sentido, y en pos de garantizar la formación integral de los estudiantes a través del acceso, en igualdad de condiciones, a una educación de calidad, establece en el Artículo 88 que "el acceso y dominio de las tecnologías de la información y la comunicación formarán parte de los contenidos curriculares indispensables para la inclusión en la sociedad del conocimiento" (Congreso de la Nación Argentina, 2006, p.18). Bajo estos lineamientos el docente a cargo de la presente experiencia, luego de la identificación de las competencias y necesidades del grupo de estudiantes, diseñó y llevó a la práctica una oferta formativa con inclusión de las TIC. Para ello, con el apoyo del equipo directivo de la institución educativa, se dio origen a un taller específico para el desarrollo de competencias digitales y se incluyeron diversos recursos de forma transversal en los distintos espacios curriculares, tales como Lengua, Matemática y Ciencias.

El principal desafío que se le presentó al docente, era diseñar una propuesta que atendiera a la diversidad del grupo fortaleciendo los vínculos entre ellos. El mismo estaba compuesto por tres estudiantes varones y dos mujeres, cuatro de ellos con discapacidad intelectual y uno con Síndrome de West. La característica en común de todos ellos, fue la necesidad de un ambiente de enseñanza altamente estructurado y la puesta clara de límites, para evitar problemas de conducta. Incluso debido a sus cortos niveles atencionales y baja autoestima, requerían de actividades cortas y motivadoras, para evitar el abandono de la propuesta. De esta manera y bajo el impulso de la formación recibida dentro del experto en TIC, dictado en la ciudad de Córdoba durante el periodo 2016-2017, el docente implementó diversas configuraciones de apoyo para transformar la propuesta educativa, tornándola más atractiva para los estudiantes. Para los cuales, el principal desafío se centró en la adquisición de nuevas competencias, principalmente digitales, para manejar los diversos recursos propuestos.

De esta forma, las diferencias individuales de cada uno de los estudiantes, fueron concebidas por el docente no como obstáculos sino 


\section{7}

como, oportunidades para enriquecer la enseñanza y el aprendizaje, a través del uso de las TIC.

\section{Objetivos}

- Desarrollar las competencias necesarias para el desarrollo integral en el contexto de la cultura digital.

- Mejorar sus problemas de conducta, niveles atencionales, inclusión social y autoestima. Que el docente sea capaz de: incluir las TIC de forma significativa y gradual, en el diseño de la oferta educativa.

\section{Desarrollo de la experiencia}

Debido a que, en la provincia de Córdoba, no se dispone de un Diseño Curricular que oriente el uso de las TIC en nivel primario, el docente a cargo de la experiencia, recurrió para determinar objetivos y competencias, al Anexo Curricular de la Ciudad de Buenos Aires. En el mismo Ripani (2014) establece algunos de los objetivos que a continuación se mencionan y que fueron desarrollados en la presente experiencia.

Las actividades previas que se gestionaron antes de la implementación de la buena práctica fueron:

Detección de necesidades, intereses y competencias individuales, respetando las cinco fases del modelo $\mathrm{M}$-free.

Diseño de proyectos transversalizados por diversos recursos TIC. Los mismos pertenecieron a las áreas curriculares de Lengua, Matemática, Ciencias Sociales y Ciencias Naturales. Las actividades propuestas en los diversos espacios invitaron a los alumnos a apropiarse significativamente de los contenidos propuestos.

Búsqueda, investigación y conocimiento de diversos recursos TIC adecuados al contenido a abordar y a las competencias a desarrollar en los estudiantes. 
Diseño de una matriz de evaluación de competencias con el fin de incluir en las propuestas de enseñanza y aprendizaje los ajustes necesarios.

En la presente experiencia las actividades se desarrollaron en tres momentos, que, si bien a continuación se presentan de forma separada, se ejecutaron de forma simultánea y/o complementaria. Incluso se mencionan solo algunos de los recursos TIC implementados, a modo de ejemplo, puesto que los mismos se especifican en su totalidad en el apartado de recursos utilizados.

1) Desarrollo de las propuestas de enseñanza y aprendizaje diseñadas en las diversas áreas curriculares.

Dentro de cada espacio curricular se desarrolló una secuencia didáctica mediada por diversos recursos TIC, los cuales fueron utilizados como disparadores de un tema, como evaluación o a modo de profundización de lo estudiado y/o trabajado. En consecuencia, los recursos seleccionados por el docente, estaban íntimamente relacionados con los objetivos y contenidos a desarrollar durante una determinada secuencia, así como también a las competencias, necesidades y estilos de aprendizaje de cada estudiante. Lográndose de esta forma la individualización de la enseñanza.

Los recursos utilizados en este sentido fueron en su mayoría, la aplicación AURASMA y los libros interactivos EDILIM.

A este respecto, es importante mencionar que, al incluirse las TIC dentro de la oferta de enseñanza y aprendizaje, los estudiantes participaron activamente en la producción y construcción de saberes. Proceso en el cual el docente actuó como guía, mediando el proceso individual de cada uno de ellos. 
Figura 38

Fabián, descubriendo y conociendo diversos seres vivos con la aplicación AURASMA

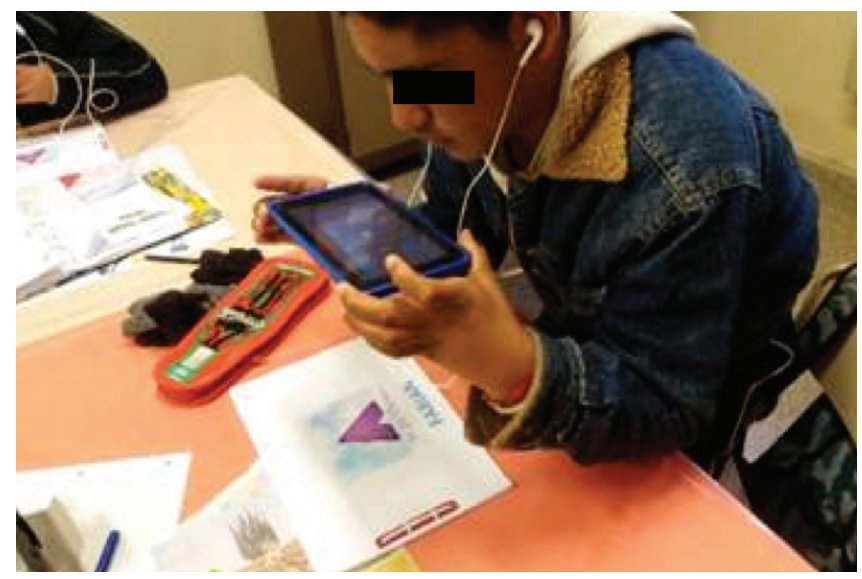

Foto: Lamberti Evelina Mariel (2016)

Figura 39

Jeremías resolviendo una evaluación de Geometría en EDILIM

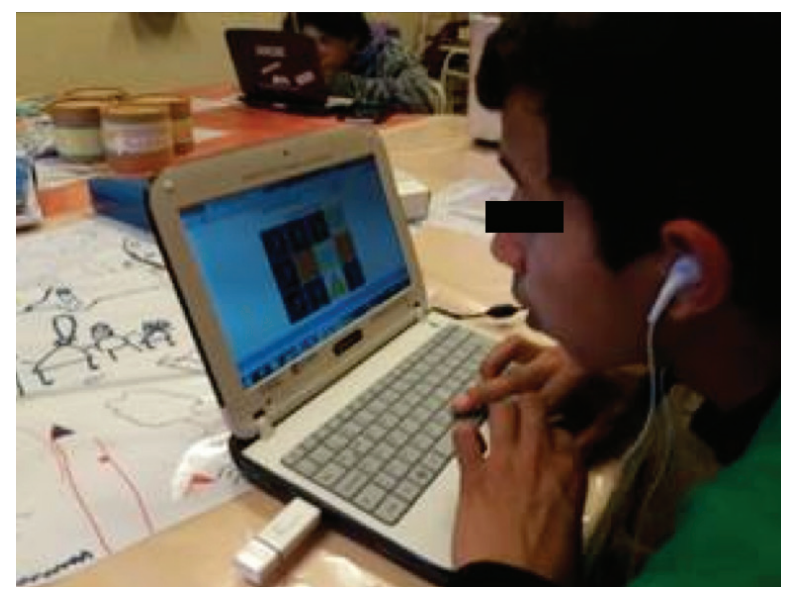

Foto: Lamberti Evelina Mariel (2016) 


\section{0}

De esta manera, al contemplarse las necesidades de cada estudiante el juego, como recursos de enseñanza, adquirió un rol protagónico "no solo porque permite a los alumnos elaborar modos complejos de simbolización y acceso al conocimiento, sino también porque es una poderosa fuente de motivación” (Ripani, 2014, p. 21). Para ello dentro de las propuestas de enseñanza se experimentó con la robótica y la programación. Así, como también se promovió el uso de diversas aplicaciones, que dentro de un entorno lúdico permitían abordar los contenidos/temas estudiados; tales como Scratch JR, Mat Ninja, Mat Duel, entre otros.

Figura 40

Lucas programando al robot DASH con la aplicación GO!

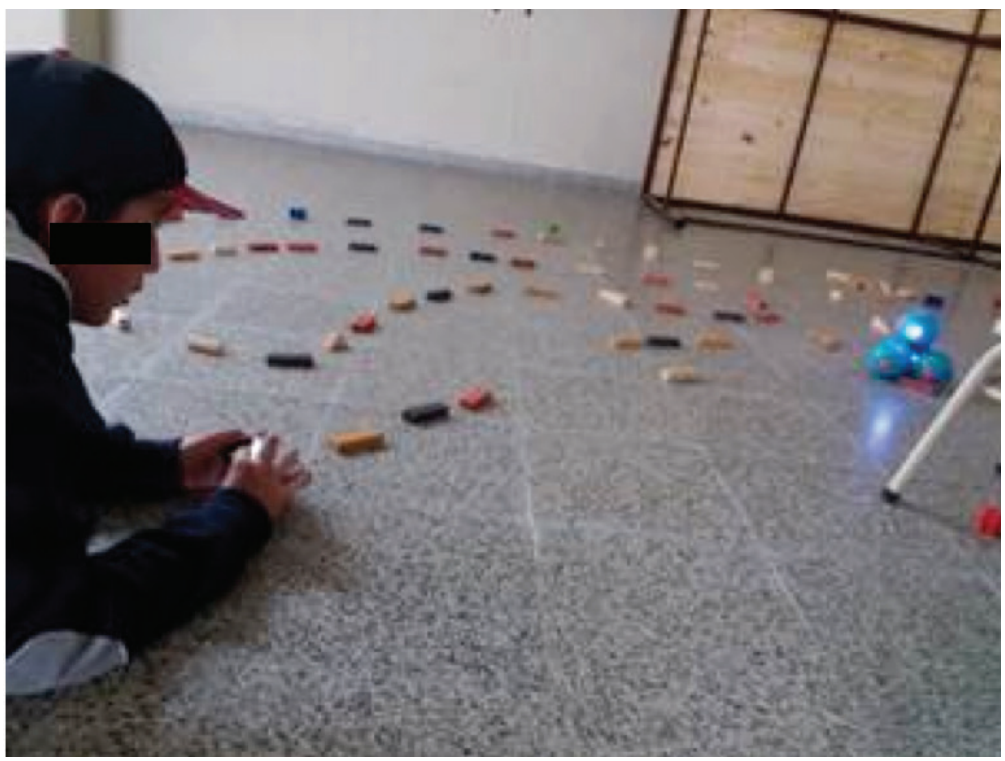

Lucas programando al robot DASH, mediante el uso de la aplicación GO!, para que realice diversos trayectos creados en forma previa

Foto: Lamberti Evelina Mariel (2016) 
Figura 41

Estimulación multisensorial por el robot DOT con la aplicación GO!

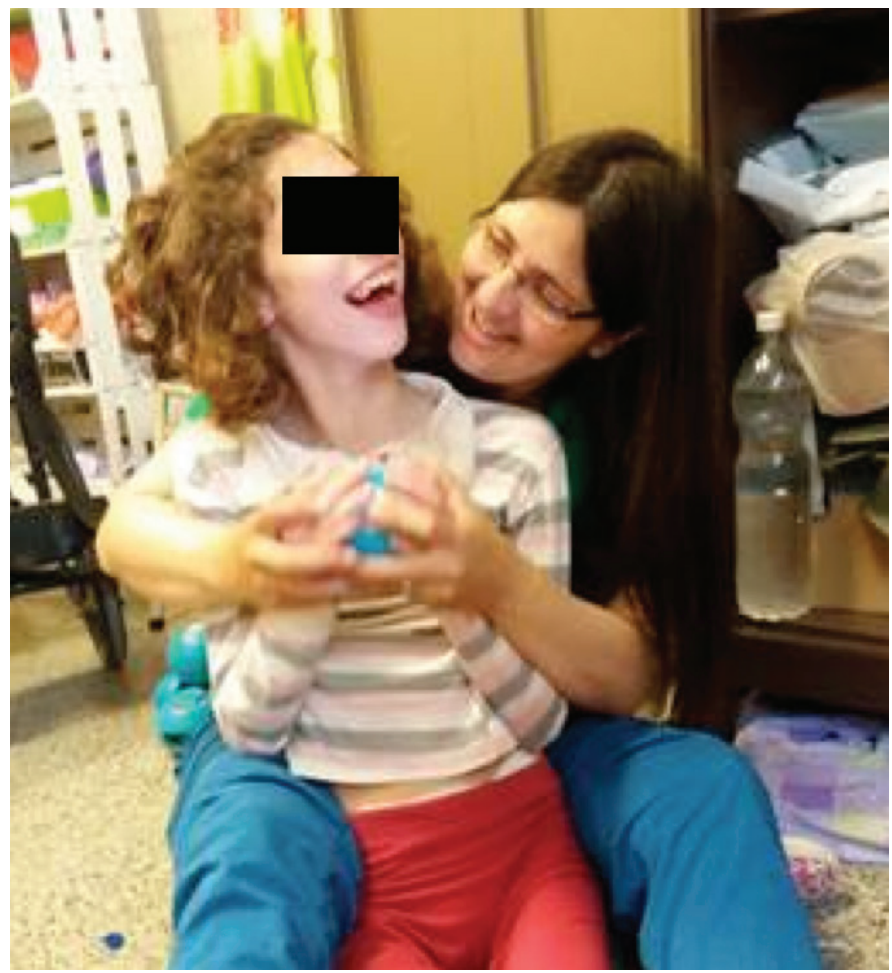

Micaela disfrutando de la estimulación multisensorial brindada por el robot DOT, programado por sus compañeros mediante el uso de la aplicación GO!

Foto: Lamberti Evelina Mariel (2016)

Otros de los recursos implementados fueron: páginas de Internet (sin conexión a la red), Microsoft Word, Microsoft Publisher, visualizador de imágenes, Webcam, Paint, entre otros. 


\section{2}

Figura 42

Jeremías, escribiendo créditos en una fotonovela, utilizando Microsoft Publisher

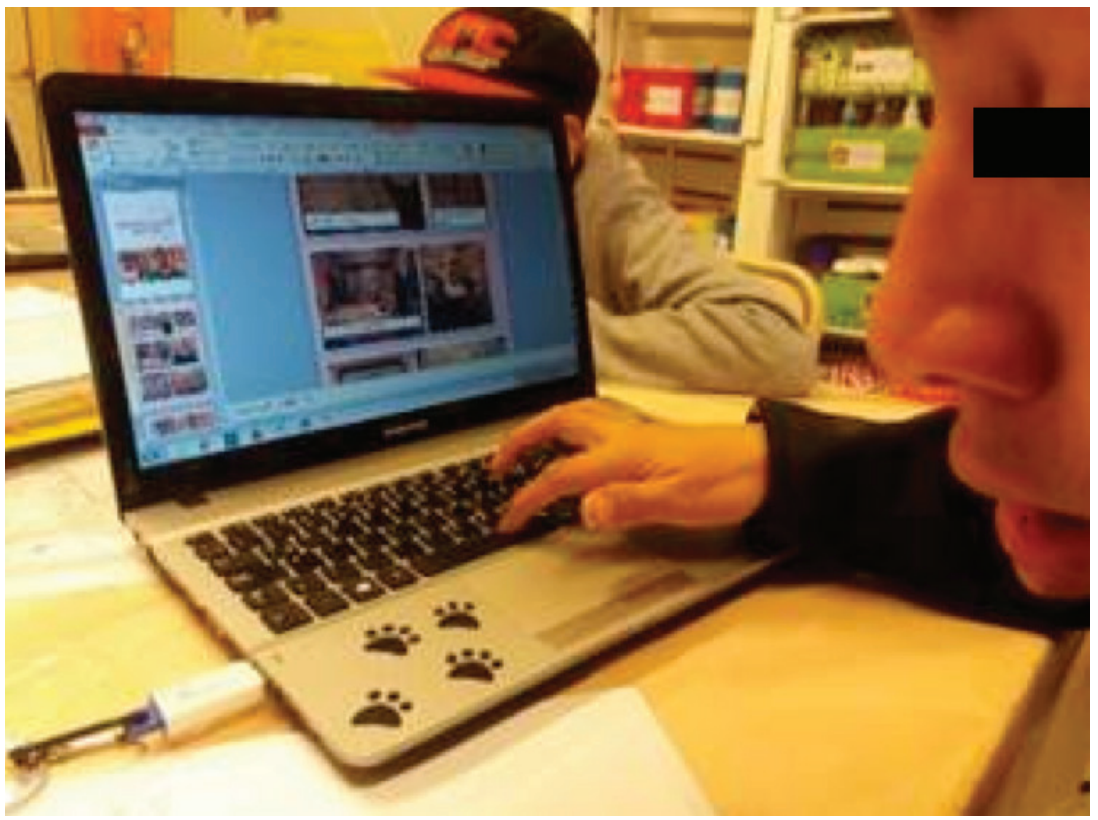

Foto: Lamberti Evelina Mariel (2016)

La mayoría de los recursos que se implementaron, se generalizaron a distintas situaciones tanto dentro de la institución, en los diversos espacios curriculares, como fuera de ella, al promover el docente la participación del grupo de estudiantes en competencias zonales y provinciales vinculadas al uso de las TIC. Así, del grupo de estudiantes, uno de ellos pasó a instancia provincial en la cual, mediante el uso del Paint debía realizar un dibujo vinculado al tema asignado. 
Figura 43

Candela, participando en las Olimpiadas de Informática, Instancia provincial llevada a cabo en la ciudad de Córdoba, Argentina

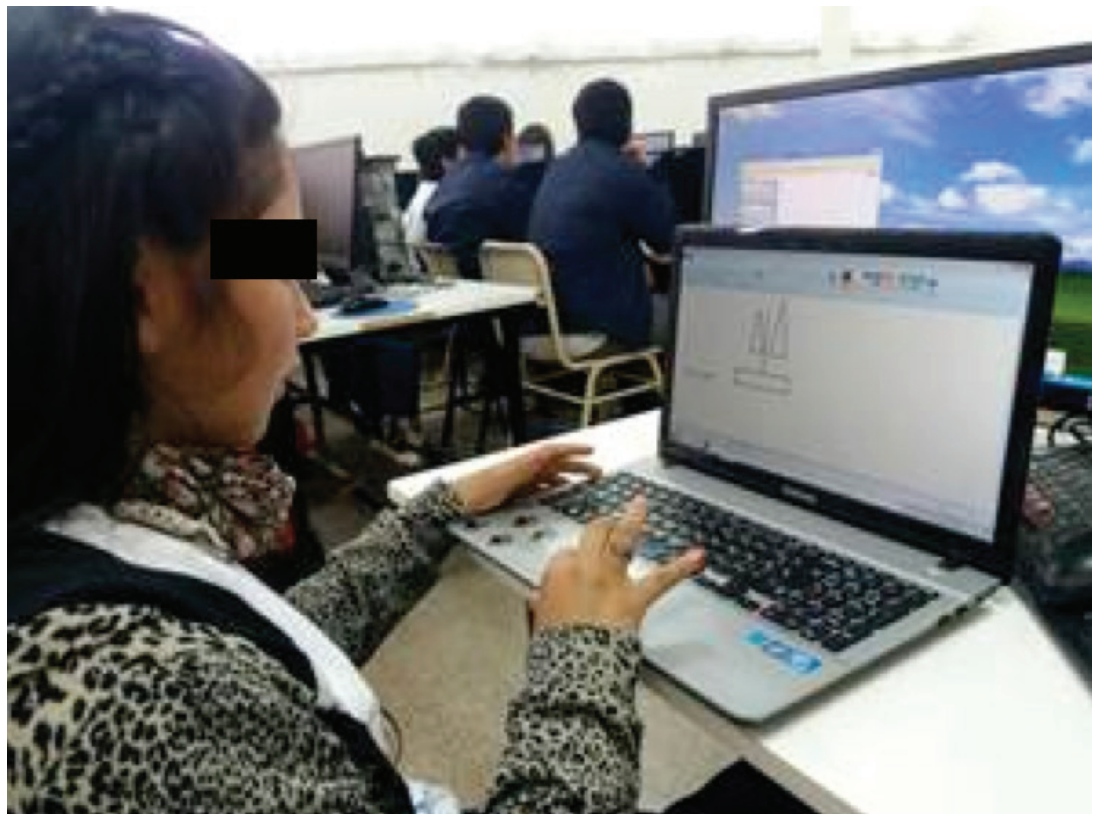

Foto: Lamberti Evelina Mariel (2016)

Por último, se menciona que al inicio de cada jornada escolar se trabajó con el PLAPHOONS para organizar las actividades por hora, asociando la imagen acompañada de la voz del docente, quien especificaba su nombre y espacio curricular a cargo. De esta manera se logró en el grupo, pero principalmente en la estudiante con Síndrome de West la anticipación y organización ante el desarrollo de las diversas propuestas, así como también se estimuló y favoreció su intencionalidad comunicativa.

La realización de ajustes durante el desarrollo de los diversos proyectos fue en función de nuevas necesidades o competencias detectadas 
en los estudiantes. Los cambios realizados por el docente se vincularon a la posibilidad de generalizar una aplicación a todo el grupo de estudiantes, debido a la complejidad o la posibilidad de un uso intuitivo en todos ellos. Así como también, en respuesta a la demanda del grupo, quienes le planteaban al docente realizar las mismas actividades que su compañera con Síndrome de West; la cual, debido a sus necesidades y competencias, requería no solo de la intervención personalizada del docente, sino también de recursos con un gran atractivo visual, en respuesta a su estilo de aprendizaje.

En cuanto a la evaluación, se caracterizó por ser de proceso durante el desarrollo de las diversas secuencias de enseñanza y aprendizaje para realizarse los ajustes antes mencionados, al finalizar las mismas, el docente de forma individual completaba una grilla de evaluación, compuesta por diversos indicadores, que detallaban los contenidos abordados y los siguientes criterios de valoración: AV (a veces), SI/NO, EP (en proceso de ser adquirido), I (independiente), CV (con ayuda verbal) y CC (con ayuda corporal). Resultados que significaban nuevos cambios en siguientes propuestas de enseñanza y aprendizaje.

Búsqueda, investigación y conocimiento de nuevos recursos TIC para superar las barreras que generaban en los estudiantes los que actualmente se estaban implementando. Las principales necesidades detectadas en los estudiantes, y que se le plantearon al docente como desafíos al momento de buscar los recursos necesarios, se relacionaban con:

- La alfabetización, ya que, para comprender aquello que debían realizar, requerían que la información sea visual y auditiva, además de gráfica, en las distintas apps y software a implementar.

- Las apps debían desarrollarse dentro de un entorno atractivo y lúdico, para evitar que abandonen la actividad propuesta, argumentando estar aburridos.

- Las apps debían promover un uso intuitivo en la mayoría de los estudiantes, para que el docente pudiera atender todas las demandas, principalmente a aquellos que requerían de interven- 


\section{5}

ción personalizada y para promover el trabajo colaborativo entre ellos, es decir entre quienes manifestaban un fácil dominio de uso de las TIC y aquellos que requerían de mayor tiempo, explicaciones y práctica para familiarizarse con el recurso.

- Las apps no solo debían ser adecuadas al contenido y objetivos de enseñanza, sino también acordes a la edad e intereses de los estudiantes, para evitar la infantilización y en consecuencia la negación, de parte de los destinatarios frente a la utilización de las mismas.

\section{Evaluación}

La evaluación se caracterizó por ser de proceso, y llevarse a cabo de forma continua a lo largo del desarrollo de las diversas propuestas de enseñanza y aprendizaje, en función de los resultados obtenidos. Para ello el docente:

Completó la matriz de evaluación, diseñada específicamente para cada proyecto.

Realizó sobre las actividades los ajustes necesarios, en función de necesidades y competencias detectadas en los estudiantes.

Reflexionó sobre la propia práctica de enseñanza.

Revisó los registros audiovisuales, capturados durante la ejecución de las diversas propuestas de enseñanza y aprendizaje, para complementar la matriz de evaluación.

\section{Logros obtenidos}

Los estudiantes se apropiaron significativamente de las TIC.

El docente logró progresiva y gradualmente integrar diversos recursos TIC en sus propuestas de enseñanza y aprendizaje. 


\section{6}

Los estudiantes lograron trabajar colaborativa y cooperativamente entre ellos.

El docente logró adaptar las propuestas de enseñanza y aprendizaje a las necesidades y competencias de cada estudiante, mediante la inclusión de diversos recursos para producir textos, gráficos, videos, etc.

Los estudiantes desarrollaron diversas competencias digitales, tales como prender y apagar los dispositivos (tableta, netbook), manejar teclas de desplazamiento, identificar y seleccionar accesos directos/iconos en el escritorio, reconocer el entorno de trabajo del procesador de texto, crear un documento nuevo, abrir un documento ya creado, crear, y organizar diapositivas en programas de presentación, entre otras.

Los estudiantes emplearon su creatividad y expresión en sus distintos lenguajes (corporal, verbal, gestual). Los estudiantes participaron activamente, en la construcción de actividades lúdicas, mediadas por el uso de las TIC. Los estudiantes lograron crear, comunicar y compartir temas estudiados a través de múltiples lenguajes de representación. Los estudiantes lograron resolver problemas con diversos recursos. Los estudiantes lograron transferir conocimientos previos para aprender a usar nuevos recursos. Por ejemplo, participaron por primera vez en las Olimpiadas de Informática, logrando uno de ellos pasar a la instancia provincial, llevada a cabo en la ciudad de Córdoba.

El docente a través de la inclusión de las TIC en sus propuestas de enseñanza logró facilitar el aprendizaje de todos los estudiantes, mediante la gestión de un proceso de retroalimentación en el cual ambos actores aprendieron mutuamente.

Los padres de los estudiantes se interesaron por la metodología de trabajo, solicitando al docente la enseñanza de los diversos recursos TIC para ser utilizados en sus hogares.

La propuesta de enseñanza y aprendizaje mediada por las TIC generó curiosidad e interés en otros docentes. 


\section{7}

Los estudiantes lograron respetar normas de trabajo y uso de los diversos dispositivos (tableta, netbook, celular) y de las aplicaciones o recursos TIC propuestos por el docente.

Los estudiantes lograron regular su comportamiento, mediante la evaluación y reflexión de la propia conducta, a través de la aplicación CLASS DOJO. Esto fue el logro más importante y gratificante para el docente, ya que muchas propuestas, antes del uso de las TIC, eran consideradas aburridas por los estudiantes, generando en consecuencia problemas de conducta.

Los estudiantes lograron interactuar entre ellos, asignando y respetando roles, así como también necesidades dentro de actividades lúdicas y juegos mediados por las TIC.

El uso del Sistema de Comunicación Aumentativa, creado en el Plaphoons, incremento la comunicación y/o expresión de la estudiante con Síndrome de West.

\section{Recursos utilizados}

Dentro de cada espacio curricular se diseñaron proyectos con actividades que incluyeron diversos recursos TIC, a fin de promover en los estudiantes el aprendizaje, el conocimiento, el juego, el pensamiento, la comunicación, la creación y el trabajo colaborativo. En todos ellos se utilizaron tabletas o las netbook entregadas por el gobierno, con recursos que no necesitaran de conexión a internet, ya que la institución educativa no dispone del mismo. Solo en algunas ocasiones se recurrió al uso del celular personal del docente para utilizar algunas aplicaciones que así lo requerían. Este último dispositivo también se implementó a la hora de programar y resolver situaciones con los robots Dot y Dash.

A continuación, se detallan las aplicaciones implementadas, con algunos de los usos que se les dio en el aula. Por último, se comparten enlaces para visualizar las producciones de los estudiantes: 
Movie Maker, ${ }^{18}$ para crear videos utilizando capturas realizadas por los estudiantes o brindas por el docente.

Visualizador de imágenes de Windows, utilizado para ver imágenes y favorecer el análisis de las mismas.

Reproductor de Windows media, para proyectar videos utilizados como disparador de un tema o para profundizar el mismo.

WebCam utilizada para capturar videos o fotografías durante la realización de una salida/visita y para registrar diversas entrevistas (material que luego, a través de su proyección favoreció la reconstrucción de las actividades realizadas).

Microsoft Word para favorecer el proceso de escritura de diversos enunciados y/o textos.

Microsoft Publisher, para crear folletos informativos.

Páginas web (sin conexión a internet) para investigar y conocer sobre un tema de estudio y para estimular el proceso de alfabetización inicial.

Libros interactivos (EdiLim), utilizados como: disparador de un nuevo tema, para indagar saberes previos, para profundizar un tema de estudio o para evaluar lo aprendido.

Aplicación: Trasportador - ON PROTACTOR: utilizando para que los estudiantes midan ángulos en objetos reales, utilizando la cámara de las tabletas. ${ }^{19}$

Aplicación: "Math Duel”, utilizada para estimular en los estudiantes el cálculo mental, y la resolución de operaciones básicas (adición, sustracción, multiplicación y división $)^{20}$.

18 Programa para editar vídeos. Link de descarga: https://goo.gl/xkmRPC

19 Disponible en: https://goo.gl/6YG1Re

20 Disponible en: https://goo.gl/cre5Ug 


\section{9}

Aplicación: “Mat Ninja”, utilizada para que los estudiantes aprendan las tablas de multiplicación. ${ }^{21}$

Aplicación: "Lupa y microscopio", utilizada para observar resultados de experimentos realizados junto a los estudiantes en el área de Ciencias Naturales. ${ }^{22}$

Aplicación: "Ciencias Naturales", utilizada junto a los estudiantes para acceder a información sobre seres vivos e inertes. Esta aplicación es totalmente accesible ya que posee un lector que en voz alta lee y marca la información disponible en la página, a medida que se avanza en la lectura, y acompaña los textos con imágenes reales. ${ }^{23}$

Aplicación: "Calculadora que habla": utilizada para que los estudiantes reconozcan números de diversa cantidad de cifras, y realicen las cuatro operaciones básicas (adición, sustracción, multiplicación y división). ${ }^{24}$

Aplicación: "AURASMA" utilizada por el docente, como disparador de un contenido a trabajar. ${ }^{25}$

Aplicación: "Geoplano Digital”, utilizado para crear diversas figuras geométricas, así como también para calcular el área y perímetro de las mismas. ${ }^{26}$

Aplicación: “@voice”, utilizada para que los estudiantes escuchen atentamente información del tema estudiado y logren por ejemplo clasificar seres vivos siguiendo un criterio propio o determinado por el docente. Esta aplicación permitió también que los estudiantes sigan una lectura, ya que marca el progreso de la misma en el texto. ${ }^{27}$

\footnotetext{
21 Disponible en: https://goo.gl/Q62ia8

22 Disponible en: https://goo.gl/Ev4yYe

23 Disponible en: https://goo.gl/FHs9nk

24 Disponible en: https://goo.gl/uXfhvz

25 Disponible en: https://goo.gl/GUKiZv

26 Disponible en: https://goo.gl/S8X3hr

27 Disponible en: https://goo.gl/2YbQW7
} 
100

Google Earth y Google Maps, utilizados junto a los estudiantes para ubicar geográficamente un lugar, para trazar un trayecto o recorrido a realizar. ${ }^{28}$

Aplicaciones: Drawing, Scribmaster y Boceto, para que los estudiantes realicen dibujos con diferentes propósitos y los guarden en formato imagen. ${ }^{29}$

Aplicación Voz-Texto y Texto-Voz, para que los estudiantes transformen mensajes orales en oraciones y textos y luego los escuchen por párrafos o el texto completo. ${ }^{30}$

Aplicaciones: Scratch JR, Lightbot y BIT BY BIT, utilizados para iniciar a los estudiantes en el lenguaje de la programación, en el trabajo colaborativo, la resolución de problemas, etc. ${ }^{31}$

Robots DOT y DASH y sus aplicaciones: GO!, WONDER, BLOCKY, PATH Y XILO, utilizados por los estudiantes para programar los robots y resolver diversas situaciones propuestas por el docente o creadas por ellos mismos. ${ }^{32}$

Videos juegos de Family, utilizados para promover en los estudiantes el trabajo colaborativo, el desarrollo de competencias digitales y el juego. Para promover la participación de todos los estudiantes, los juegos se realizaron con el uso del dispositivo Makey Makey.

Aplicación: CLASS DOJO, utilizado junto a los estudiantes para evaluar su comportamiento y acordar estrategias o normas para su mejora. ${ }^{33}$

28 Disponible en: https://goo.gl/JXbKww

29 Disponibles en: https://goo.gl/JrclKN; https://goo.gl/7Pk7D8; https://goo.gl/aJkVjz

30 Disponible en: https://goo.gl/1rinPd

31 Disponibles en: https://goo.gl/6gjvS9; https://goo.gl/VRGnc); https:/goo.gl/2GUopg

32 Disponible en: https://goo.gl/5X5CPz; https:/goo.gl/tMkHUj; https:/goo.gl/ QdeR7F; https://goo.gl/SbSdtm; https://goo.gl/xwMSLM 


\section{1}

Programa PLAPHOONS, utilizado para crear un comunicador personalizado para que uno de los estudiantes trabaje el calendario, es decir para anticipar las actividades a realizar dentro de la jornada escolar. ${ }^{34}$

Programa: SÍGUEME, utilizado para trabajar la atención. ${ }^{35}$

Programa: BLUESTACKS, utilizado para instalar en la computadora las mismas aplicaciones que se disponían en la tablet, con el objetivo de que la estudiante con Síndrome de West pudiera participar en las actividades en igualdad de condiciones que sus pares. ${ }^{36}$

\section{Producciones de los estudiantes}

Área: Ciencias Sociales, producción audiovisual efeméride 20 de junio-Día de la bandera. ${ }^{37}$

Área: Lengua: producción audiovisual de noticias locas creadas a partir de un cuento. ${ }^{38}$

Área: Lengua, uso del Plaphoons para anticipar las actividades de la jornada escolar. ${ }^{39}$

Área: Lengua, uso de la aplicación BOCETO para aprender a escribir el nombre propio. ${ }^{40}$

Área: Ciencias Naturales: uso de la aplicación AURASMA para descubrir y conocer seres vivos. ${ }^{41}$

34 Disponible en: https://goo.gl/jNiKeH

35 Disponible en: https://goo.gl/VmLWDH

36 Disponible en: https://goo.gl/yzfgE1

37 Disponible en: https://goo.gl/cCjmnv

38 Disponible en: https://goo.gl/YZkGpx

39 Disponible en: https://goo.gl/XKbe74

40 Disponible en: https://goo.gl/UxBaZY

41 Disponible en: https://goo.gl/3qpWvR 
102

Área: Ciudadanía y Participación, producción audiovisual: fotonovela "Historia de un amor exagerado", trabajo sobre respeto a la diversidad y derechos del niño. Realización de entrevistas a cargo de los estudiantes. ${ }^{42}$

Área: Taller de TIC, uso del programa “Sigueme” para trabajar atención. ${ }^{43}$

Área: Taller de TIC, programación con los robots DOT y DASH..$^{44}$

Área: Taller de TIC, uso de videojuegos de Family con el dispositivo Makey Makey. ${ }^{45}$

\section{Aclaraciones}

El docente se encargó no solo de la búsqueda de los diversos recursos, sino también de su instalación previa, en los diversos dispositivos de trabajo, para poder ser utilizados en el aula.

En caso de no visualizar los recursos audiovisuales de las producciones de los estudiantes, solicitar acceso al siguiente correo: evelinamlamberti@gmail.com

Los estudiantes que participaron de la propuesta cuentan con la debida autorización de sus familiares, para que sus imágenes sean publicadas y utilizadas en presentaciones con fines educativos.

Los recursos implementados, tales como las tabletas, el dispositivo Makey y los robots Dot y Dash fueron comprados por el docente, ya que la institución educativa, al ser pública, no cuenta con los recursos económicos necesarios para realizar tales inversiones.

El uso de las aplicaciones varió en cada estudiante, en función de sus necesidades, competencias y estilo de aprendizaje. Lo que significa que no todos utilizaron la totalidad de las aplicaciones anteriormente descriptas.

\footnotetext{
42 Disponible en: https://goo.gl/GZQw4N

43 Disponible en: https://goo.gl/dd3VPf

44 Disponible en: https://goo.gl/r4UUNw

45 Disponible en: https://goo.gl/ZmqcFh
} 